\title{
THE RELATIONSHIP BETWEEN MATERNAL PSYCHOLOGY, FAMILY, AND CULTURE WITH PERCEPTION OF BREAST MILK INSUFFICIENCY IN BREASTFEEDING MOTHERS OF SUMUR BATU PUBLIC HEALTH CENTER, LAMPUNG INDONESIA
}

\author{
Nova Muhani ${ }^{1}$, Ririn Wulandari ${ }^{1}$, Nurul Arayastuti ${ }^{1}$, Dhiny Easter Yanti ${ }^{1}$, Dessy Hermawan ${ }^{2}$, Siti Nena \\ Sefililaisya ${ }^{3}$ and Wulan Angraini ${ }^{4}$ \\ ${ }^{1}$ Faculty of Public Health, Malahayati University Bandar Lampung, Indonesia \\ ${ }^{2}$ Departement of Nursing, Faculty of Medicine, Malahayati University Bandar Lampung, Indonesia \\ ${ }^{3}$ Medical Section, PT. Pertamina Panjang Lampung, Indonesia \\ ${ }^{4}$ Departemen of Public Health, Faculty of Health Science, Muhammadiyah University of Bengkulu, Indonesia
}

Corresponding author: Nova Muhani

Email: muhaninova@gmail.com

\section{ABSTRACT}

This study aims to get an overview of the perception of breast milk insufficiency seen from maternal psychological factors, family factors, and culture factors. Qualitative research used a phenomenological approach using source and method of triangulation techniques. Data were collected by using in-depth interviews with seven main informants of mother and husband or family (perception of breast milk insufficiency) and four key informants, i.e. program holders of Sumur Batu Public Health Center and cadres. Focus Group Discussions (FGD) was conducted with five mothers to collect information about the perception of breast milk insufficiency. The reason for mothers not exclusively breastfeeding was that mothers had felt that their breast milk was low and it had not met the needs of their baby. Psychological factors that affected the mother's perception of breast milk insufficiency were lack of confidence about the adequacy and content of breast milk. The family had contributions in making decisions about giving nutrition to babies. The habit of giving formula milk had become a culture in the community. Creating innovative programs in educating the public by involving families, doing collaboration across sectors by the establishment of breastfeeding support groups, and the implementation of assertive rules for health workers/agencies that do not promote exclusive breastfeeding.

Keywords: Maternal psychology, Family, Culture, Perception of breast milk insufficiency

\section{INTRODUCTION}

Breastfeeding is a natural process. Generally, there are no mothers who cannot breastfeed. However, mothers need to learn to be able to breastfeed properly. There are obstacles to exclusive breastfeeding. The reasons for mothers not exclusively breastfeeding vary widely. ${ }^{1}$ The main cause of stopping breastfeeding is that the mother feels that the milk she produces is lacking. ${ }^{2}$ The most reason for mothers, not exclusive breastfeeding is that they feel they don't have enough breast milk (23.7\%). ${ }^{3}$ The main reason for terminating exclusive breastfeeding is that mothers think that breast milk alone is not enough for babies (52.9\%). ${ }^{4}$ Babies who are not given breast milk exclusively are given additional foods such as formula milk or animal milk (42.6\%), castor oil or ghee $(18.4 \%)$, water $(24.5 \%)$ and/or sugar water or honey $(18.8 \%){ }^{3}$

Perception of breast milk insufficiency is a perception or self-assessment of a mother who believes that she does not have a sufficient supply of breast milk to meet her baby's needs ${ }^{2}$. One of several factors that influence the establishment of the perception of breast milk insufficiency is the lack of maternal knowledge regarding exclusive breastfeeding, especially the adequacy of breast milk for their babies. ${ }^{2}$

Perception of breast milk insufficiency can generally be considered to occur if mothers stop breastfeeding exclusively for the following reasons: there is no breast milk, breast milk is lacking/insufficient, and the baby remains fussy after feeding. Perception of breast milk insufficiency is one of the main causes of the failure of exclusive breastfeeding in the world. ${ }^{5}$ However, it is not yet known whether this perception is a physiological or psychological problem. In recognizing whether the perception of breast milk insufficiency is a physiological or psychological problem, it is necessary to know the causes. If it is not based on a clear cause then the perception of breast milk insufficiency is most likely a psychological problem. However, if it is associated with physiological causes such as malnutrition, it can be considered as a series between physiological and psychological problems. ${ }^{6}$ 
Perception is a process of interpreting information obtained through the human sensory system The establishment of perception is influenced by psychological factors, family factors, and cultural factors. ${ }^{7}$.

The low coverage of exclusive breastfeeding in some developing countries is still very concerning, i.e. China (21\%), India (55\%), Nigeria $(17 \%)$, Mexico (31\%), and Indonesia (42\%). ${ }^{8}$ The World Health Assembly has set a goal to increase exclusive breastfeeding by at least $50 \%$ by $2025 .{ }^{9}$ Currently only 23 countries meet the 2030 global goal of exclusive breastfeeding in the first six months and it has been targeted to increase the rate of exclusive breastfeeding at least $60 \% .{ }^{10}$

According to the Basic Health Research year 2018 in Indonesia, the percentage of providing only breast milk in the last 24 hours without a history of giving prelacteal feeds at 6 months of age $(37,3 \%) .{ }^{11}$ While the government, in the Strategic Plan of Ministry of Health year 2015-2019, targeted coverage of exclusive breastfeeding of $50 \% .{ }^{11}$ The percentage of babies who received exclusive breastfeeding until the age of six months is $29.5 \%$. The proportion of exclusive breastfeeding in Lampung Province is $(33.1 \%)^{11}$ the coverage very low, the still below the national average. The trend of achieving exclusive breastfeeding in Bandar Lampung City is $42.07 \%$. The lowest exclusive breastfeeding coverage is Sumur Batu Public Health Center (28.17\%) the low coverage of breastfeeding in Sumur Batu Public Health Center which is influenced by knowledge, Perception of Breast Milk Insufficiency, maternal Psychology, Family, and Culture.

Mothers who cannot let their babies cry continuously even after they have been breastfed, provide additional food/drinks so that the babies turn out to be silent. mothers think that babies who cry constantly means they are still hungry because the breast milk is lacking. This opinion has a background and is rooted in the traditions and continues to be entrenched in society sources about culture that affect breastfeeding. ${ }^{6}$ This qualitative study aims to find out the perception of breast milk insufficiency in breastfeeding mothers seen from maternal psychological factors, family factors and, cultural factors.

\section{METHODS}

This research used a qualitative design with a phenomenological approach. To maintain the validity of the data, triangulation was carried out, in this study it was carried out by triangulation of sources and method of triangulation.

Data collection was carried out between July August 2018 in Sumur Batu Public Health Center working area, which included Gulak Galik subdistrict, Sumur Batu and Pengajaran. The population in this study were breastfeeding mothers in Sumur Batu Public Health Center.
Samples were obtained by snowballing sampling. Main informants were obtained based on recommendations from key informants with similar problem considerations and background characteristics. Data collection was carried out by in-depth interviews with 7 main informants (mothers with perceptions of less breastfeeding), 7 main informants (husband / mother's family with less breastfeeding perspective), and 4 key informants, namely 1 person at Sumur Batu Public Health Center and 3 cadres of each village in the working area of Sumur Batu Public Health Center. Focus Group Discussion (FGD) was conducted on 5 mothers who had a perception of less breastfeeding.

The instruments used in this study were in-depth interview guidelines and FGD guidelines. The citation of the informant's answer was coded, namely $A$ for the statement of the informant's Perception of breastfeeding deficiency (PKA), B for the statement of the PKA husband / family informant, C for the statement of the key informant and $F$ for the statement of the informant in the FGD.

In-depth interviews and FGDs were recorded by using a recording device, then transcribed and combined with notes during data collection in the field. There were three lines of qualitative data analysis, namely data reduction, data presentation, and conclusion drawing. All data that has been collected was analyzed using a content analysis approach, which was to compare the results of the data that have been grouped, analyzed with existing theories and literature reviews, and completed with document review. The discussion was carried out in a descriptive way of the input, process and output elements. Presentation of results is done in formal and informal forms. The validity check was done by source and method triangulation.

This study was approved by Ethics Review Committee for Involving Research. Human Research Subject, Malahayati University health research ethics commission. Certificate of Approval number 248 / EC / KEP-UNMAL / 5/2018. That the authors obtain written consent from all participants prior to their involvement in this learn.

\section{RESULTS}

The characteristics of the informants consisted of seven breastfeeding mothers who were interviewed consisting of 3 primiparous and 4 multiparous people. Their ages ranged from 18 to 36 years. Only 2 women worked as private employees and the rest were housewives. The highest level of education was SMA / K, two of whom were junior high school graduates and married at a young age, namely 17 years. Their children's ages at the time of the study were 12 days to 5 months, with 3 babies being female and 
4 babies being male. 3 of the women lived alone, while the other 4 lived with their parents. The tribe inherited from their family was 2 women from Padang tribe, 3 women from Sundanese tribe, 1 woman from Javanese tribe and 1 woman from Aceh tribe.

\section{Condition during breastfeeding}

All informants revealed that they did not exclusively breastfeed and provided additional food because they felt that their breast milk is lacking so it does not meet the needs of the babies.

"My child was given breast milk mixed with bottle milk because there was no breast milk when it was a newborn. Breast milk was produced a little." (A1)

"I just gave SUN to my baby because my baby didn't breastfeed, after two weeks of dryness. When my breast milk was dry, my baby was given without the formula milk, but he/she was not full. Recently the baby was given SUN because the breast milk didn't come out, it just came out a little, I saw it sorry. "(A.6)

All informants had provided additional food when the baby was less than 6 months old. This statement was strengthened by husbands. The following are the excerpts:

"The baby drank breast milk and formula milk because she said that the breast milk was not enough for the baby." (B1)

"Initially the baby was given breast milk and then it was given formula milk with the SUN for a little bit because she said there was less breast milk for the baby." (B6)

The statement was strengthened by the key informants, the following are the excerpts:

"So, it was very difficult for us to find mothers that exclusively breastfeed, that give only breast milk to their baby. Most of them gave formula milk to the baby when the baby was one or two months old. It was my experience as long as I worked." (C1).

"Yes, we are told to mothers to exclusively breastfeed, but there were still many mothers who don't exclusively breastfeed their children. Some mothers breastfeed, but not exclusively breastfeed. They gave formula milk. It was like that." (C3).

Based on interviews, all informants revealed that they did not provide exclusively breastfeed and provided additional food such as formula milk and baby porridge for the reasons that the breast milk was little and not enough for the baby's needs. This statement was reinforced by husbands and the key informants. They argued that the small amount of breast milk will not be enough to meet the needs of the babies so they must provide additional food to them. Therefore, the babies were not fussy and his nutritional needs were met.

\section{Perception of Breast Milk Insufficient}

To illustrate the perception of breast milk insufficient, several questions about the conditions related to insufficient breast milk were asked to all informants. The informants did not exclusively breastfeed their babies because they thought that the breast milk was little and did not meet the needs of their babies. The following are the excerpts:

"It was like that the breast milk came out just a little, even if we force it, it just drops." (A4)

"The breast milk didn't come out, it was just a little, it's not enough for the baby." (A5)

The breast milk production from each informant was different as long as they breastfed their babies. Most said that the breast milk only came out a little and half said that the breast milk stopped coming out. The following are the excerpts:

"Before 40 days, the breast milk came out just a little. So, it was mixed with formula milk. How little that is... if some mothers experienced breast swelling and milk drop out... I didn't. After being pumped it just comes out." (A4).

"The breast milk came out very little for two months, now it doesn't come out at all." (A2).

All informants said that they did not know the causes of lack of breast milk but they had a presumption. The following were the excerpts:

"I did not know, people said that it caused by drugs, but I did not take any medicine like Chinese medicine. People said Chinese medicine could reduce the breast milk. I just took the 'gabus' pill. Is it because I was afraid too? because if we experienced breast swelling, we will feel pain. So I wanted to breastfeed but I was afraid, be afraid, finally, the breast milk dried, hehe" (A6)

"My mother said it was caused by eating chili sauce. But I didn't something weird after giving birth, I was afraid, too... so I don't know why." (A7).

\section{The Causes of Low Breast Milk}

All informants said that they intend to give breast milk to their babies and have tried to increase breast milk production. The following were the excerpts:

"Yes, I intended to give breast milk, but how about the situation. If I were rich, it won't increase my expenses. My efforts were... I ate vegetables, fruits, lots of water so that the breast milk comes out... like that." (A1)

"I tried to eat a lot so that I couls have a lot of breast milk, but it still didn't affect me." (F4) 
"The efforts were ... from eating a lot, people said to eat bean leaves, 'katuk' leaves. There was also a 'katuk' pill that I drank, too. The results were there but not directly, after a month the breast milk was smooth."

Regarding the ease of getting formula milk as a substitute for breast milk, most of the informants said that it did not affect their intention to give breast milk. They still wanted to give breast milk to their babies but they could not. The followings were the excerpts:

"It's not a pleasure to give formula milk. It was better to give our breast milk, but how about it, hehe." (A5)

"I wondered how... our condition was. there was no breast milk, so we have to provide formula milk." (A6)

A small number of informants said there was no problem with formula feeding. The followings were the excerpt:

"No, I asked first to the midwife, could or not. After all, I was afraid if I didn't breastfeed, it could be stale, so it was said it's not good. "(A3)

This statement was reinforced by the husbands. "Actually, how about it ... it was really happy because it's close, because it's already a need for the baby too. It's not a burden, as long as we have sustenance." (B3)

"Because she couldn't feed the baby, that's the only way, at least if there's no money, that's confusing If the father wasn't there, then I bought it. If the baby was not given formula milk, what should he eat." (B2)

That the baby was fussy and kept crying was used as a sign that babies didn't get enough breast milk. The followings were the excerpts:

"He cried and cried and didn't sleep well. He was not calm, just like ... starving. At that time, it was 11 or 12 o'clock when he cried. So, I went to the pharmacy to buy the formula milk. He was given it, after that he calms down." (A4)

"He cried to death even though he had been breastfeeding." (A7)

"He kept going mad, crying, fussing." (B4)

To find out whether it was true that the baby is deficient in breast milk, mothers were asked about the method to measure/assess the amount of breast milk production, baby weight gain and frequency of baby's pee. The followings were the excerpts:

"The method was pumping. From pumping could be seen the adequacy... I get 20-30 $\mathrm{ml}$ of breast milk. Baby's weight increased, Alhamdulillah. It was often. After drinking he peed." (A4)
"I saw from the frequency of her suckling and the frequency she was fussy. If she was not fussy maybe she got enough breast milk. How much. saw lots of diapers that had to be washed." (B6)

Breastfeeding, diet, and rest patterns might affect the amount of breast milk production. The followings were the excerpts:

"It was often, this often happened until it could not be calculated. He suckled not only one or two minutes, he suckled for half an hour until he felt tired. I ate a lot, greens, it was said that it was good for breastfeeding. I have enough rest, after all, he was with his grandmother at night, he's not fussy." (A3)

"That was not counted. He suckled for half an hour but it didn't count for several a number of times, every time he cried, every time he's fussy. Usually, when he would be bathed, he couldn't stand hunger, he would scream. Oh, I ate a lot, I ate vegetables, eggs, fishes, just like that. I just didn't eat chili sauce because I was afraid I will diarrhea like before." (A7)

Informant's experiences and knowledge can influence their behavior in breastfeeding. Half of the informants said that they gave breast milk because they had experience using formula milk before. The followings were the excerpts:

"As far as I know, compared to formula milk, breast milk was better for children's growth. It makes children smart. In the past, the brothers were given formula milk all the time, because I was busy working. Now, I give formula milk, for example, if the baby had been breastfed but she was still fussy, I add formula milk or when I go." (A1)

"Since the first child, I gave formula milk and breast milk. But I don't give breast milk to my second child. He was breastfed only for three days." (A5)

\section{Perception of Breast Milk Insufficiency from Psychological Effect}

All informants were asked about psychological things that made them feel that their breast milk was a little. The informants argued different opinions. Most of them said it was due to stress. Others said it was due to physical limitations. Some of the informants said it was due to their history. The followings were the excerpts:

"I was confident, but yes, it was because of stress, pain. became uncomfortable. In the past. the first child, the second, they suckled only on the left breast. Now I gag my right breast. The position of the right nipple is somewhat different because it's not sucked, so I gag it. If it blisters, move here, move here, it blisters again. I was confused, both breasts blisters. It feels pain when the scuffed breasts are choked. 
If it doesn't scuff, I breastfeed the baby. So, yes, I stop breastfeeding." (A6)

"Yes, it was. Because the nipples were flat, so it was difficult for him to suckle. I felt tired, too. I can't do it even though I tried." (A2)

"There was... because of the high blood pressure... It made a mind.. if I give birth with a midwife, if I have high blood pressure, it couldn't.. so I had a cesarean section. It made a mind, until now I still think about that." (A5)

The statement was reinforced by the opinion of the husband and the results of the FGD. The followings were the excerpts:

"The reason was stress. Stress might have made breast milk not come out." (B7)

"Maybe I experience stress, it might be because of tiredness, it must be stressful, because of staying up late after giving birth, exhausted." (F3)

When asked about their feelings if they could exclusively breastfeeding, all informants said that they were happy and wanted to breastfeed their babies exclusively. The followings were the excerpts:

"Incredible, really happy, that's why I want exclusively breastfeed for six months. It feels... that's an achievement. 'I exclusively breastfeed' I said to my friends. After undergoing and feeling it, oh like this." (A4) "It's nice, yes, it was pleasant because we could breastfeed our child, we could successfully become mothers." (A5)

This information was reinforced by the informants during the FGD. The following was the excerpt:

"It's great if you could give breast milk. because I have never been able to exclusively breastfeed." (F3)

All informants said that they felt sad and worried about the nutritional adequacy of their babies because the babies were not given exclusive breastfeeding. The followings were the excerpt:

"I was worried, sis.. I was afraid that she would not have enough nutrition." (A1)

This information is reinforced by the husband and the results of the FGD. The followings were the excerpts:

"It's sad for sure, I could give breast milk in the past but why now I couldn't." (B6)

"Yes, I'm worried. The breast milk has more nutritional content than formula milk, then we had to prioritize breast milk first." (F5)

The responses from the informants regarding their feelings when giving up breastfeeding or providing supplementary food (formula milk) and the efforts made to overcome these feelings, could be seen from the following excerpts:
"I thought, that time, after giving birth, my breast milk didn't come out at all, huh, whether I wanted it or not. Because my child didn't suckle, he didn't get anything. I had tried to breastfeed, it didn't come out at all, even a drop, it didn't come out, two days after giving birth the breast milk came out a little. I wanted to continue breastfeeding, sis. When it's full, then it just came out by itself, but not much." (A7) "I was worried. I was afraid... It didn't guarantee that it was health, not sterile. We just have to do it because of the situation. I tried to eat a lot so that breast milk becomes a lot, so he didn't drink too much formula milk. Alhamdulillah, increased. I've tried to pump my breast milk, but he didn't want to drink it. So, until now, I still give formula milk, only when I left. "(A1)

This information was reinforced by informants during the FGD. The following was the excerpt:

"I am forced, ma'am, because I can't see the baby crying like a starving person like that. I still consume nutritious food so that my milk is good, then I give formula milk regularly." (F5)

\section{Perception of Breast Milk Insufficiency from Family Effect}

In making decisions about exclusive breastfeeding or other actions in the breastfeeding process, all informants said that the decision-maker was them and their husbands, but there was interference from people who were considered more understanding like parents. The following was the excerpt:

"I was alone with my husband, but because my breast milk did not come out, my mother told me to give formula milk." (A2)

This information is reinforced by the husbands and the results of the FGD. The followings are the excerpts:

"If we were still ... her grandmother... because she knew more." (B3)

"I was with my husband. but using formula milk... my mother told so... she said that rather than baby cries." (F2)

All informants said that the whole family supported breastfeeding, but when there was a problem in the process of breastfeeding the family also did not forbid to provide other foods as a substitute for breast milk. The following was the excerpt:

"All of them support it because it was better to breastfeed than formula milk but when you gave formula milk it was also not forbidden because it was the need for him, so it was forced because of the situation. But it's still a business and lots of breastfeeding rather than formula milk. "(A1) 
This information is reinforced by another informant's husband. The following was the excerpt:

"I, as a husband, really support her, if she could give breast milk, but if she couldn't, how come... there was no other way than formula milk." (B5).

When asked about the existence of a habit or belief in breastfeeding that was often done in families, most informants said that they have a habit of abstinence. The following was the excerpt:

"Oh yeah, that's a lot, my mother said if I eat spicy food, I will get diarrhea. If I eat eggs, I will suffer from itching. If I eat fishes, I will be allergic... we were afraid of that. My mother-in-law said I should not eat hot food I have to wait until it cools down or my tongue will turn white. If breastfeeding, give the right breast first, then the left breast." (A7)

This information was strengthened by informant's husband/family. The following was the excerpt: "Usually she is not permissible to eat eggs, fishes. It is said that she will suffer from itching, the wound will be healed for a long time." (B6).

\section{Perception of Breast Milk Insufficiency from Culture Effect}

When asked about matters relating to culture in breastfeeding behavior, most informants said that they provided additional food because they see this habit of people in their environment. The followings were the excerpts:

"Yes, I was given formula milk by my mother when I was a kid." (A2)

"Yes, people here are used to giving formula milk. Some people said There are also people who said it was better to give breast milk than formula milk. It was more economical, not spending money. But how... if we didn't have breast milk, did we want to see our children cry?" (A5)

This information was strengthened by statements from the informant's husband/the closest family and the results of the FGD. The followings were the excerpts:

"Many of my neighbors here provided formula milk to their children, I just followed it." (A5)

"My child couldn't suckle, it's difficult, so my mother told me to give formula milk, I just followed her, she also said that I was given formula milk when I was a kid." (F2)

All informants were asked about breastfeeding traditions/habits/myths in their environment. Most informants said there was no tradition/belief/myth of breastfeeding. The followings were the excerpts:
"I didn't know, there's nothing like that." (A3)

"I didn't know about the environment is, I was also a newcomer here, but it didn't seem to exist." (B6)

Some informants also expressed their opinions that in their neighborhood there was a belief. The followings were the excerpt:

"There were more or less things like that, but I didn't believe that. If someone felt ashamed to breastfeed, then the breasts would be loose but I leave them alone." (A1)

"There was a prohibition on eating this and that, If I think it didn't make sense then I didn't follow it." (F5)

Based on the results of interviews conducted with the main informants and it was strengthened by the results of interviews with the husband/family and FGD results, various arguments revealed by informants showed that there were still many mothers who felt that their breast milk was not sufficient and there was a desire to add formula milk.

\section{DISCUSSION}

Based on in-depth interviews and FGD with informants, it was known that exclusive breastfeeding according to the definition of World Health Organization (WHO), "no other food or drink, not even water, except breast milk (including milk expressed or from a wet nurse) for 6 months of life, but allows the infant to receive ORS, drops and, syrups (vitamins, minerals, and medicines)" was very difficult to do.

\section{1) Condition During Breastfeeding}

Breastfeeding self-efficacy consisted of two parts: the belief that behavior will produce specific results and the belief that you can successfully conduct the behavior to achieve the desired results. $^{12}$ The findings showed that only eight mothers continued to provide exclusive breastfeeding during the first four weeks. The main problems of mothers not continuing exclusive breastfeeding were (a) insufficient breast milk, (b) nipple pain, (c) returning to work or school, and (d) low economic status. ${ }^{13}$ Unexpected complications were an annoying experience including infection, pain, and low supply of breast milk. Then, usually, mothers would give up in fulfilling their expectations. Broken nipples, difficulty in attachment, or insufficient milk supply were the main problems in stopping the breastfeeding process during the early postpartum period. ${ }^{14}$

The most frequent reason for exclusive breastfeeding termination was that breast milk was insufficient. Mothers often used complementary foods such as formula milk, castor 
oil, water, sugar water, or honey water to wean or stop breastfeeding. The perception of breast milk insufficiency was a common phenomenon throughout the world and the typical response was to provide infant supplementary foods from an early age. ${ }^{3}$ Complementary foods could be introduced to infants with the assumption that breast milk alone would not meet the needs of infants when they were almost six months. ${ }^{15}$ Knowledge, intention to breastfeed, and social media were reported as facilitators. While the inhibiting factors are perception, job, and promotion of formula milk. Whereas families, health care, and traditional food were facilitators and inhibitors of maternal behavior in exclusive breastfeeding. ${ }^{16}$

\section{2) Perception of Insufficient Breast Milk}

One of the causes of exclusive breastfeeding failure was the provision of prelacteal feeds when the babies were not yet six months old. In this study, besides breastfeeding, mothers also gave formula milk and baby porridge since the baby was born. Generally, prelacteal feeds were given because the breast milk has not come out, breast milk was a little, there was a problem with the breast (flat nipple and nipple blisters). This finding is consistent with previous studies in Turkey and Mexico, which reported that the perception of insufficient milk was prevalent in postpartum mothers who did not practice exclusive breastfeeding. ${ }^{17}$

The reasons that were often argued by mothers with the perception of breast milk insufficiency include fussy babies, crying after breastfeeding, and bad weight gain. Thus, mothers believed and considered that these conditions are signs that their breast milk cannot meet the needs of their babies. To meet the needs of the babies, they immediately provided formula milk, which actually would only disrupt the lactation physiology. Their worries could affect the letdown reflexes which would make it difficult for them to breastfeed their babies. ${ }^{18}$

The theory of self-efficacy Bandura developed and adapted to a wide range of literature on breastfeeding concept known as the Breastfeeding Self-Efficacy consists of three dimensions related to the success of the breastfeeding technique, interpersonal thoughts, and support. Dimensions techniques means all related to physical activity, a person's a person and the actions required to achieve success in breastfeeding. While the intrapersonal confidence is on the attitudes, beliefs, and perceptions of mothers about breastfeeding. The third dimension is the support that covers all the things that help mothers successfully breastfeed both emotionally and physically. ${ }^{19}$

\section{3) The Cause of Low Breast Milk}

Generally, others thought that babies who cried constantly means that they were still hungry because the breast milk was lack. This view had a background that came from traditions that were entrenched in society. The perception of breast milk insufficiency usually arose in a few days after the breasts were not full and babies often ask for suckling. This was a natural thing. The breasts were not tender even though they produced a lot of milk. Babies often asked for breastfeeding because breast milk was quickly digested and the stomach quickly became empty.

Other studies explained that mother's education, knowledge, and experience were predisposing factors that had positive effects on the success of exclusive breastfeeding. While early initiation of breastfeeding was a strong enabling factor for the success of exclusive breastfeeding. On the other hand, formula milk advertising, giving information about the implementation of exclusive breastfeeding should be done especially during antenatal care, not after childbirth. ${ }^{5}$

In line with this study, the previous experiences of mothers in breastfeeding effected had an effect on their behavior of providing breast milk and formula milk as a substitute for breast milk. There were health workers who advise mothers to give formula milk to their babies. Health workers should be role models for the community to succeed in the exclusive breastfeeding program.

Maternal perception of breastfeeding was an active process of individuals to interpret the meaning of the breastfeeding adequacy, exclusive breastfeeding, and early complementary feeding. Internal and external factors, including environmental factors, affect individual perceptions. Getting attention, thought process, and information about the breastfeeding adequacy, exclusive breastfeeding, and complementary feeding are obtained through learning or derived from community cultural beliefs, personal characteristics, personality, individual conditions, and individual experiences of breastfeeding and providing complementary foods.

Mothers with a good perception of breastfeeding adequacy would exclusively breastfeed without providing early complementary feeding. On the contrary, mothers with a bad perception of breastfeeding adequacy may argue that their breast milk was lack, so they did not exclusively breastfeed.

\section{4) Perception of Insufficient Breast Milk from Psychological Effect}

Emotional factors could affect the production of breast milk. The secretion activity of the mammary glands constantly changes by the psychological/psychiatric effects experienced by mothers. Mother's feelings could inhibit or increase oxytocin hormone release. Feelings of fear, anxiety, anger, sadness, anxiety, resentment, embarrassment, or severe pain 
would affect the oxytocin reflex, which suppresses the release of breast milk. ${ }^{20}$

In this study, most informants experienced selfdistrust of the production and quality of breast milk. The informants said that they felt uncomfortable due to the pain that they experienced so that they became afraid to breastfeed their baby. It made the milk production decrease. Stress problems due to fatigue, history of comorbidities, make mothers have a mind. Physical abnormalities, i.e. flat nipples, were factors that cause a reduction in breast milk production. Insufficient breast milk would affect the mother's confidence. It created the perception of breast milk insufficiency that would affect the mother's mind and the release of the hormone oxytocin. Disruption of hormone oxytocin release would cause interference of breast muscle contractions so that the breast milk was blocked. On the other hand, because breast milk was decreased, mothers would rarely breastfeed. It affected the release of prolactin hormone which would reduce milk production.

The physical effects of discomfort and pain was that many women felt shocked during breastfeeding. Pain and discomfort affect the mother's feelings. Therefore, the mother and baby relationship were disturbed. It raised doubts and interferes breastfeeding process The unpredictable natures of maternal physical implications including pain, discomfort, certain body sensations that are associated with suctioning, leaking, sticking, nipple bleeding and uterine contractions were causes for weaning. ${ }^{21}$

Female psychology was defined as something related to psychological concerns and intimacy experienced by a woman during her lifetime, including adolescence, menstruation, pregnancy, breastfeeding, and menopause. ${ }^{22}$ The family has contributions in the decision of providing nutrition to the babies. In this study, the influential person in making decisions was grandmother (mother/mother-in-law). The mother was influenced by the family in breastfeeding, both by copying and being told directly by the family. Supports had a big contribution to the success of breastfeeding. One support that played a role in exclusive breastfeeding was the support of spouse or husband. In this study, support from family and husband in practicing exclusive breastfeeding was still lacking. Some husbands did not play a direct role in helping mothers during the exclusive breastfeeding practice.

\section{5) Perception of insufficient breast milk from Family Effect}

This study showed the inadequacy of the family's role in exclusive breastfeeding practice in the work area of Sumur Batu Public Health Center. In carrying out their role, the family must know first about exclusive breastfeeding, the benefits for infants and mothers, and how to overcome the problem if breast milk is not smooth. This study indicated that family understanding of exclusive breastfeeding is not yet sufficient. Therefore, the most important thing that the family must have was a good understanding of the benefits of exclusive breastfeeding, which were not obtained even from the most expensive formula milk. Besides adequate knowledge, the family must always pay attention to the maternal psychological condition. As we know, maternal psychological conditions would make the mother was able to produce breast milk smoothly. A husband often did not pay attention to the psychological condition of his wife. Sometimes it was considered sufficient if husbands had fulfilled his family's livelihood. Even though a husband as the head of the family should pay attention to all aspects of the needs of his wife and children.

Some men reflected that their initial desire for their partner to breastfeed has been weakened by witnessing some challenges faced when they try to breastfeed. The feeling most strongly expressed was that it was inappropriate for men to try to influence their partner in a decision that would not directly affect them. ${ }^{23}$

This was consistent with other studies that showed that fathers played an important role in successful breastfeeding and enhancement of breastfeeding rates. Data showed that fathers had an important role in a mother's decision about feeding the baby. A father could play an active role in the success of breastfeeding by providing emotional support and other practical assistance, such as changing diapers or belching the baby. ${ }^{20}$

Breast milk insufficiency related to the informants' belief in consuming foods. They ate foods low in animal protein. They only consumed tofu, tempeh, vegetable broth, and did not eat fishes and eggs. The informants said that eating fish and eggs can cause the wound and episiotomy sutures to be difficult to heal. Therefore, they practiced the diet.

A Study in Kudus City explained that environmental factors had positive effects on exclusive breastfeeding. Environment was the conditions that exist around humans and influence the development and behavior of people or groups. ${ }^{24}$ It has been noted that maternal physical environments and family relationships affect the diet. More specifically, maternal household workload, lifestyle, and reproductive schedule change the mother's decision regarding the sustainability of breastfeeding. In short, the overall social and institutional environment in which mothers were located was considered as an important predictor of breastfeeding behavior. ${ }^{25}$ Lactation support with systematic actions were needed to ensure mothers breastfeeding universally, that was by providing information about required fields and supports. Beside In addition, making feedback could ensure mothers 
receive and understand the key information about breastfeeding. It was a modifying factor increase the duration of breastfeeding. ${ }^{26}$

One of the efforts to increase exclusive breastfeeding rates among teenage mothers was by implementing lactation-related training for health workers, especially nurses, the people in order to provide holistic nursing care both in clinical settings and in the community. Doing counseling starting from the prenatal period and giving the concept of exclusive breastfeeding was better by including the main family participation, i.e. husband and grandmother so that the exclusive breastfeeding rates could be increased. ${ }^{27}$

\section{6) Perception of insufficient breast milk from Culture Effect}

This research showed that most informants said that they provided additional food because they saw this habit of people in their environment. A Study in Semarang showed that maternal knowledge and skills about exclusive breastfeeding was still limited. Maternal knowledge was also influenced by the experiences of others and by seeing colleagues, the surrounding environment, and the closest relatives. Seeing other people's experiences inspires mothers to do the same. ${ }^{28}$ in Indonesian culture, mothers tend to believe that small breasts produce smaller amounts of breast milk and older mothers' breast milk is of lower quality. ${ }^{17}$

A Study in Kanigoro, Blitar, in 2013, showed that treatment such as counseling could provide changes in individual attitudes. Maternal knowledge of exclusive breastfeeding affected the mother's attitude. There was also another factor that influenced maternal attitude, i.e. socio-cultural factors that form the mother's attitude. ${ }^{29}$

This study in Korogocho and Viwandani slums in Nairobi, practices provided a breadth of knowledge about the social and cultural beliefs and practices that influence breastfeeding. Some of the beliefs aligned with the WHO recommendations on breastfeeding and positively influence the translation of the recommendations into practice, these include the common belief that colostrum was natural medicine and that breast milk promoted brain and intellectual development. ${ }^{30}$ An optimal breastfeeding, optimal child feeding, and care practices would be successfully developed by those positive beliefs. Prelacteal feeding was common amongst ethnic groups from the western region of the country, it prevented the breastfeeding after birth which occurred in other African countries, ${ }^{31}$ this was also a major cause for delayed initiation of breastfeeding, and consequent increased risks of neonatal infections and death. All unsuccessful exclusive breastfeeding and all breastfeeding
Community based interventions regarding the promotion of optimal maternal and infant nutrition should dispel the practice of prelacteal feeding were associated by this culture effect. ${ }^{32}$

This study described prelacteal feeding to infants in the form of formula milk and baby porridge because mothers feel that the breast milk production is low. The informants said that prelacteal feeding was done on advice and by seeing the habits of parents and people around them and based on their experiences. The experiences and education of mothers during childhood would affect their attitudes and appearances related to breastfeeding behavior. A woman who lived in family or community that have regular breastfeeding habit or often saw other women regularly breastfeed their babies would have a positive perception of breastfeeding, and vice versa. Poor maternal knowledge about breastfeeding, lack of knowledge about the risks of pralacteal feeding, and misconceptions about breastfeeding were important predictors of pralacteal feeding practices.

This belief was contrary to modern science that stated that consumption of protein would help healing wounds and decrease the incidence of injuries because of infection due to poor hygiene. This was important because in some cases, the mother's failure to provide exclusive breastfeeding occurs due to the wrong understanding of the family. Mothers have difficulty resisting or opposing because the one who gave formula milk to the baby was their mother-in-law or their biological mother. This event would be minimized when mothers and families have good knowledge about exclusive breastfeeding and strong agreement and commitment of supporting in providing exclusive breastfeeding.

It is important to develop innovative programs to increase public knowledge. The innovation can be done by involving in educating about exclusive breastfeeding. Good knowledge and family support will increase the motivation to provide exclusive breastfeeding. Therefore, mothers will not easily be influenced by inhibiting factors of breastfeeding. It is recommended to organize workshops with the health workers of the family Public Health Center so that they have good knowledge about exclusive breastfeeding and can help the exclusive breastfeeding program run optimally. It is recommended to collaborate across sectors to establish the breastfeeding support groups, consisting of community members and The Family Welfare Movement cadres, and to implement an assertive rule for health workers/agencies that do not promote exclusive breastfeeding. 
Maternal psychology is influential in the breast milk production process, the production of breastmilk greatly affects the sustainability of exclusive breastfeeding. Mothers who are not confident about the adequacy and quality of breast milk due to physical limitations, discomfort due to postpartum pain and stress due to fatigue tend to provide additional foods or complementary foods. In making decisions about feeding the baby, has important contributions. The grandmother (parents/mother-in-law) is an influential person because she is considered to be more understanding so that she is used as a role model. The family breastfeeding habits in the environment affect the decision to provide additional food or to replace breast milk with formula milk. It occurs because mothers see the habits and experiences of also people around them.

\section{Conflict of interest}

The authors declare no potential conflict of interest.

\section{REFERENCES}

1. World Health Organisation W. Breasfeeding [Internet]. World Health Organization. 2018. Available from:https://www.who.int/topics/br eastfeeding/en/

2. Prabasiwi A, Fikawati S, Syafiq A. Exclusif Breasfeeding and Perception of Insufficient Milk Suplya. Kesmas Natl Public Heal J [Internet]. 2015;9(3):282. Available from: http://journal.fkm.ui.ac.id/kesmas/ article/view/691/458

3. Nishimura H, Krupp K, Gowda S, Srinivas V, Arun A, Madhivanan P. Determinants of exclusive breastfeeding in rural South India. 2018; Available from:https: / /www.ncbi.nlm.nih.gov/ pmc/articles/PMC6114539/pdf/1300 6_2018_Article_178.pdf

4. Ratnayake HE, Rowel D. Prevalence of exclusive breastfeeding and barriers for its continuation up to six months in Kandy district, Sri Lanka. Int Breastfeed J [Internet]. 2018;13(1):18. Available from: https://www.ncbi.nlm.nih.gov/pmca rticles/PMC6085653/pdf/13006_2018 _Article_180.pdf

5. Fikawati S, Syafiq A. Causes of the Success and Failure of the Practice of Exclusive Breastfeeding. Kesmas Natl Public Heal J [Internet]. 2009;4(3):120. Available from:http://journal.fkm.ui.ac.id/kes mas/article/view/184

6. Fikawati S, Syafiq A. Maternal Nutritional Status and Breast Milk Insufficiency Perception. J Kesehat Masy Nas. 2011;6(6):249-54.

7. Thoha M. Organizational Behavior Basic Concepts and Its Applications [Internet]. 24th ed. Jakarta: Rajawali Press; 2015. 376 p. Available from: https: / /books.google.co.id/books?id =PR9DwAAQBAJ\&pg=PA318\&dq=thoh a+Perilaku+Organisasi+Konsep+Dasar + dan+Aplikasinya\&hl=id\&sa $=$ X\&ved $=0$ ahUKEwjxnNqq7vDmAhXGZSsKHXogA nsQ6AEILjAB\#v=onepage\& $q=$ thoha Perilaku Organisasi Konsep Dasar dan Aplikasinya\&f $=$ false

8. World Health Organization. Nurturing the health and wealth of nations: the investment case for breastfeeding. Unicef. 2017

9. World Health Organization. Global Nutrition Targets 2025 Breastfeeding Policy Brief [Internet]. Vol. 7. Geneva; 2012. Available from: https://apps.who.int/iris/bitstream/ handle/10665/149022/WHO_NMH_NH D_14.7_eng.pdf

10. World Health Organisation W. Tracking Progress for Breastfeeding Policies and Programmes: Global breastfeeding scorecard 2017. 2017; Available

from:https://www.who.int/nutrition /publications/infantfeeding/globalbf-scorecard-2017.pdf

11. ministry of Health RI. Basic Health Research [Internet]. Jakarta; 2018. Available from: esmas.kemkes.go.id/assets/upload/d ir_519d41d8cd98f00/files/Hasilriskesdas-2018_1274.pdf

12. Kaski K, Kvist LJ. Deep breast pain during lactation: A case-control study in Sweden investigating the role of Candida albicans. Int Breastfeed J [Internet]. 2018;13(1):1-9. Available from:

https: / internationalbreastfeedingjo urnal.biomedcentral.com/articles/10 $.1186 / \mathrm{s} 13006-018-0167-8$

13. Thomas J. Barriers to exclusive breastfeeding among mothers during the first four weeks postpartum. 2016;1-108. Available from: https: / /scholarworks. waldenu.edu/c gi $/$ viewcontent.cgi?article $=3300 \&$ con 
text=dissertations

14. Neupane JE, Kiragu $R$, Kandel $S$. Knowledge, attitude and challenges of exclusive breastfeeding among primigravidas [Internet]. Centria University; 2014. Available from: https: / /pdfs.semanticscholar.org/ad e4/44d8b488482e6173fe4d41f011c76 9f941a4.pdf

15. Adugna $B$, Tadele $H$, Reta $F$, Berhan $Y$. Determinants of exclusive breastfeeding in infants less than six months of age in Hawassa, an urban setting, Ethiopia. Int Breastfeed J [Internet]. 2017;12(1):4-11. Available from:

https:/ /www.researchgate.net/publi cation/320816752_Determinants_of_ exclusive_breastfeeding_in_infants_l ess_than_six_months_of_age_in_Haw assa_an_urban_setting_Ethiopia

16. Thepha T, Marais D, Bell J, Muangpin $S$. Perceptions of northeast Thai breastfeeding mothers regarding facilitators and barriers to six-month exclusive breastfeeding: Focus group discussions. Int Breastfeed J [Internet]. 2018;13(1):1-10. Available from:

https://www.ncbi.nlm.nih.gov/pmc/ articles/PMC5885310/pdf/13006_201 8_Article_148.pdf

17. Sandhi A, Lee GT, Chipojola R, Huda $\mathrm{MH}$, Kuo SY. The relationship between perceived milk supply and exclusive breastfeeding during the first six months postpartum: a cross-sectional study. Int Breastfeed J [Internet]. 2020;15(1):1-11. Available from: https: / / internationalbreastfeedingjo urnal.biomedcentral.com/articles/10 .1186/s13006-020-00310-y

18. Komalasari. Analysis of factors that affect the inadequacy of breast milk in mothers who have babies aged 0-12 months in the Pancoran Depok health center [Internet]. indonesia; 2012. Available

from: http://lib.ui.ac.id/file?file=digital/2 0291994-S-Komalasari.pdf

19. Kurniati N. The Importance of Breastfeeding Self Efficacy for Successful of Exclusive Breastfeeding. In: 4th ICRIEMS Proceedings [Internet]. 2017. p. 39-44. Available from:

http://seminar.uny.ac.id/icriems/sit es/seminar.uny.ac.id.icriems/files/p rosiding2017/B08 Nurul Kurniati.pdf
20. Roesli U. Get to know exclusive breastfeeding [Internet]. VII. Sudaro Y, editor. Jakarta: Trubus Agriwidya, Anggota IKAPI; 2013. 64 p. Available from:

https: / /books.google.co.id/books?id $=\mathrm{zWDmh8QBIkMC \& printsec}=$ frontcove r\&hl=id\&source=gbs_ge_summary_r\& $\mathrm{cad}=0 \# \mathrm{v}=$ onepage\& $q \& \mathrm{f}=\mathrm{false}$

21. Karen A. Wambach SMC. Breastfeeding Experiences of Urban Adolescent Mothers. J Pediatr Nurs [Internet]. 2009;24(4):244-54. Available from: https: / /www. pediatricnursing.org/ar ticle/S0882-5963(08)00174-7/fulltext

22. Brown A, Davies R. Fathers' experiences of supporting breastfeeding: Challenges for breastfeeding promotion and education. Matern Child Nutr [Internet]. 2014;10(4):510-26. Available from: https://www.ncbi.nlm.nih.gov/pmc/ articles/PMC4282396/pdf/mcn00100510.pdf

23. Hounsome L, Dowling $S$. ' The mum has to live with the decision much more than the dad'; a qualitative study of men' s perceptions of their influence on breastfeeding decisionmaking. Internastional Breastfeed [Internet]. 2018;13(3):1-10. Available from:https: / /internationalbreastfeed ingjournal.biomedcentral.com/track /pdf/10.1186/s13006-018-0145-1

24. Maharlouei N, Pourhaghighi A, Raeisi H, Zohoori D, Lankarani KB. Factors Affecting Exclusive Breastfeeding , 0 riginal A rticle. Int J Community Based Nurs Midwifery [Internet]. 2018;6(3):260-71. Available from: https://www.ncbi.nlm.nih.gov/pmc/ articles/PMC6048001/pdf/IJCBNM-6260.pdf

25. Zakar R, Zakar MZ, Zaheer L, Fischer F. Exploring parental perceptions and knowledge regarding breastfeeding practices in Rajanpur , Punjab Province , Pakistan. Internastional Breastfeed J [Internet]. 2018;13(24):1-12. Available from: https://www.ncbi.nlm.nih.gov/pmc/ articles/PMC6029391/pdf/13006_201 8_Article_171.pdf

26. Leurer MD, Misskey E. “ Be positive as well as realistic ": a qualitative description analysis of information 
gaps experienced by breastfeeding mothers. Internastional Breastfeed J [Internet]. 2015;10(10):1-11. Available from: https://www.ncbi.nlm.nih.gov/pmc/ articles/PMC4363194/pdf/13006_201 5_Article_36.pdf

27. Rohmah FD, Rasni H, Hardiani RS. Adolescent Mothers Breastfeeding in 0 until 6 month infant at Karangbayat Village Sumberbaru Sub-District Jember Regency: Phenomenological Study. pustaka Kesehat [Internet]. 2016;4(3):583-9. Available from: https: / / jurnal.unej.ac.id/index.php/ JPK/article/view/6168

28. Tariku A, Biks GA, Wassie MM, Gebeyehu A, Getie AA. Factors associated with prelacteal feeding in the rural population of northwest Ethiopia: a community crosssectional study. Int Breastfeed J [Internet]. 2016;11(14):1-7. Available from:

http: / /dx.doi.org/10.1186/s13006-

016-0074-9

29. Lina Handayani1, Aprilia Rahmadani2 AS. Effect of Breasfeeding Class to Knowledge and Attitude. 5 Urecol Proceeding [Internet]. 2017;(February):1-8. Available from: http://lpp.uad.ac.id/wp-

content/uploads/2017/05/1. -lina-1- 8.pdf

30. Wanjohi M, Griffiths P, Wekesah F, Muriuki P, Muhia N, Musoke RN, et al. Sociocultural factors influencing breastfeeding practices in two slums in Nairobi , Kenya. Int Breastfeed J [Internet]. 2017;1-8. Available from: http://dx.doi.org/10.1186/s13006016-0092-7

31. Legesse M, Demena M, Mesfin F, Haile D. Prelacteal feeding practices and associated factors among mothers of children aged less than 24 months in Raya Kobo district, North Eastern Ethiopia: A cross-sectional study. Int Breastfeed J. 2014;9(1):1-8.

32. Edmond KM, Kirkwood BR, AmengaEtego S, Owusu-Agyei S, Hurt LS. Effect of early infant feeding practices on infection-specific neonatal mortality: An investigation of the causal links with observational data from rural Ghana. Am J Clin Nutr [Internet]. 2007;86(4):1126-31. Available from: https://pubmed.ncbi.nlm.nih.gov/17 921392/ 